\title{
INCOMPLETE UNDERSTANDING OF CONCEPTS AND KNOWING IN PART WHAT SOMETHING Is
}

\author{
ANDRÉ J. ABATH \\ Federal University of Minas Gerais (UFMG), BRAZIL \\ ajabath@ufmg.br
}

\begin{abstract}
Burge (1979) famously argued that one can have thoughts involving a concept $C$ even if one's understanding of $C$ is incomplete. Even though this view has been extremely influential, it has also been taken by critics as being less than clear. The aim of this paper is to show that the cases imagined by Burge (1979) as being ones in which incomplete understanding of concepts is involved can be made clearer given an account of direct concept ascriptions - such as "Peter has the concept of arthritis" - according to which these ascriptions are to be analysed in terms of ascriptions of the knowledge of what something is. The upshot is that the cases imagined by Burge (1979) can be explained is terms of the idea of subjects knowing in part what something is.
\end{abstract}

Keywords: concepts $\bullet$ knowledge $\bullet$ knowledge-wh $\bullet$ partial knowledge $\bullet$ Burge $\bullet$ incomplete understanding

\section{Introduction}

In his "Individualism and the Mental" (1979), Burge strongly argues in favour of a view according to which one can have thoughts involving a concept $C$ even if one's understanding of $C$ is incomplete. Burge supports this view by presenting us with a case in which an individual, affected by arthritis, has a number of true beliefs on the matter - such that he is affected by arthritis, that some of its symptoms are a stiffening of the joints, pain in the wrists and fingers and so on. Surprisingly, however, he also believes - falsely - that he has arthritis in his thigh. We thus seem to have a case in which one has thoughts involving a concept - that of arthritis - even though one's understanding of the concept is incomplete; after all, in having false beliefs regarding his condition, the individual has "misunderstood the concept of arthritis", as Wikforss (2001, p.219) puts it. According to Burge, moreover, the phenomenon of incomplete understanding of concepts is in no way extraordinary or unusual. Rather, it is applicable to a large number of concepts, and producing a list of these concepts would be "largely a matter of patience" (Burge 1979, p.84). ${ }^{1}$ 
Burge's view remains extremely influential ${ }^{2}$, but a number of critics have taken it to be less than clear. Bach (1987, p.267), for example, writes: "As for me, I have no idea what it is to think with a concept that one incompletely understands. That is because I have no idea what it is to understand a concept over and above possessing it". Wikforss (2017, p.7) considers a similar worry by suggesting that it is natural to think that "using a concept just is grasping it, thinking a thought containing it. How, then, could there be a gap between employing or possessing a concept and understanding it?". The worry, then, is that it is unclear what it means for one to use a concept in thought - and thus to possess it — while at the same time incompletely understanding it.

It is to be expected that this worry can only be relieved if we are told more about issues such as concept possession and concept use, so that we have a framework within which the worry can be discussed more clearly. Indeed, Peacocke (1992) and Burge (1993) himself, for instance, have attempted to develop views regarding concepts according to which one can reasonably take the cases introduced by Burge (1979) into account as long as certain distinctions are made. Peacocke's (1992) idea is to make a distinction between concept possession and concept attribution. The possession conditions for a concept $C$ state what is required for one to master $C$ fully. Thus, given Peacocke's account, there is no sense in which a subject can satisfy the possession conditions for $C$ while incompletely understanding it. Cases of incomplete understanding should be dealt with not in terms of a concept's possession conditions, but rather in terms of its attribution conditions, which are much weaker. As Peacocke puts it:

The attribution conditions for RED, the conditions under which something of the form "x believes that_red_" is true, are much weaker than the possession condition. The following are jointly sufficient for such an attribution to be true.

I) The subject is willing sincerely to assert some sentence of the form "_red_" containing the word "red" (or some translation of it).

II) He has some minimal knowledge of the kind of reference it has (e.g. that it is a color word).

III) He defers in his use of the word to members of his linguistic community. (Peacocke 1992, p.29)

Peacocke's (1992), however, is focused on providing a systematic and detailed account of concepts in terms of concept possession, and his views on concept attributions are in no way developed.

Burge (1993) instead appeals to a distinction between concepts and conceptions. Concepts can be seen as being individuated by definitions, in the sense of conditions 
that are in fact necessary and sufficient for something to fall under a concept. But these definitions - which Burge (1993, p.314) calls "metaphysically correct" - need not and are frequently not known by us, actual thinkers. Rather, actual thinkers work with conceptions of concepts, which are, roughly, what we are able to explicate or spell out regarding what falls under a concept or regarding what a word expressed by a concept - such as "arthritis" - means. These explications may well turn out to be incomplete or even wholly incorrect in comparison to the metaphysically correct definitions that individuate concepts. If that is so, then "one may think with a concept even though one has incompletely mastered it, in the sense that one associates a mistaken conception (or conceptual explication) with it" (Burge 1993, p.317).

Now, while it may seem promising to take the phenomenon of incomplete understanding into account in terms of conceptions - which are aspects of a subject's psychology - the account of concepts themselves — especially the idea of metaphysically correct definitions of concepts - is not sufficiently developed in Burge (1993), and their ontological status remains unclear. At any rate, my aim here is not to develop either Peacocke's distinction between concept possession and concept attribution or Burge's distinction between concepts and conceptions in order to take the phenomenon of incomplete understanding into account. Rather, what I propose to do is to introduce a new framework - one focused on direct concept attributions, such as "Alice has the concept of arthritis" - and to try and show how the cases imagined by Burge (1979) as involving incomplete understanding of concepts can be clearly explained within this framework as cases in which subjects know in part what something is. I will structure the paper as follows. In section 2, I introduce a framework according to which direct concept ascriptions should be analysed in terms of ascriptions of the knowledge of what something is, a kind of knowledge-wh. In section 3, I argue that the cases made famous by Burge (1979) as being of incomplete understanding of concepts can be accounted for within the framework here introduced in terms of the gradability of ascriptions of the knowledge of what something is; more specifically, as cases in which one knows in part what something is. I then develop this view by considering three difficulties related to it.

\section{Concept ascriptions, the knowledge of what something is and knowledge-wh}

Burge (1979) is concerned to establish the phenomenon of incomplete understanding given a pre-theoretical view of concepts - so much so that he trades the word "concept" for "notion", one that carries less theoretical commitments. In doing so, Burge suggests that, pre-theoretically, possessing or having concepts - or notions can be roughly understood in terms of knowing what something is. He writes, for 
instance, that "understanding the notion of contract comes roughly to knowing what a contract is" (1979, p.75). A similar idea is voiced, for instance, by Travis (2000), when, in characterising traditional views of concepts, he writes that "... 'has the concept of a pig' is just philosopher's talk for knows what a pig is (or, perhaps, knows what it is for a thing to be a pig)" (Travis 2000, p.17, author's italics). The point, then, is that - pre-theoretically at least - having a concept $C$ for a given $X$ can be taken as a matter of knowing what $X$ is.

For the present purposes, the suggestion is that direct ascriptions of concepts ${ }^{3}$ are to be analysed in terms of ascriptions of the knowledge of what something is. So, for instance, a direct concept ascription such as

(1) Alice has the concept of arthritis

is to be analysed in terms of

(2) Alice knows what arthritis is.

More specifically, the idea here is that when we are ascribing a concept of $X$ to our conversational partners, we are actually ascribing to them the knowledge of what $X$ is. ${ }^{4}$ But why should this analysis be of any theoretical gain? One reason for believing it to be so is the following: there is a growing interest in linguistics and in the philosophy of language in ascriptions of knowledge-wh, involving, for instance, ascriptions of knowledge where, knowledge who, knowledge why, knowledge when and knowledge what, which includes the knowledge of what something is. The attempt here is to provide a semantical framework powerful enough so that it can work for all of these ascriptions ${ }^{5}$ - even if adaptations have to be made for different cases. In order to present the standard framework on the issue on its broad lines, consider (3):

(3) Alice knows who came to the party in Patricia's house last night.

A central aspect of this framework is that ascriptions of knowledge-wh such as (3) involve indirect or embedded questions, namely, the clause headed by the whword (Karttunen 1977). Thus, in (3) the embedded question is who came to the party in Patricia's house last night. Now suppose that Lucas, Mark and Anna, and only them, came to the party. How then should we understand (3) in terms of its truth-conditions? There is controversy here, but according to an influential account (Karttunen 1977), (3) is true if and only if Alice knows the true, exhaustive (or complete) answer to the question embedded in (3), who came to the party in Patricia's house last night, where an exhaustive answer here should mention, of all the people that came to the party in case, that they did come. That is, (3) is true if and only if Alice knows that Lucas, Mark and Anna came to the party in Patricia's house last night. ${ }^{6}$ 
But now consider (4), an ascription of knowledge-where to Alice:

(4) Alice knows where to buy Italian newspapers in New York City.

As to be expected, Italian newspapers are sold in many places in NYC. But clearly, in order for (4) to be true, Alice need not know, of all these places, that she can buy Italian newspapers there. Rather, (4) is true if and only if Alice knows, of some place in NYC, that it is a place where she can buy Italian newspapers. ${ }^{7}$ That is, (4) is true if and only if Alice knows a true answer to the question embedded in it, where to buy Italian newspapers in New York City. ${ }^{8}$

These cases are useful so that we can grasp the standard semantical account for ascriptions of knowledge-wh. It can be stated thus: An ascription of knowledge-wh to a subject $S$ is true if and only if $S$ is in a knowledge relation to propositions that truly answer the question embedded in its wh-clause.

This thesis is purposely non-specific when it comes to answers. It allows that propositions may count as the true answer to questions embedded in ascriptions of knowledge-wh, as true answers to them, and it even allows for other options that have not been considered in the discussion regarding (3) and (4) above.

Let us now return to (2) - "Alice knows what arthritis is" - understood as an analysis of (1). Given that (2) is an ascription of knowledge-wh, it is to be expected that its truth-conditions can also be understood in terms of the standard semantical framework for these ascriptions. So, (2) involves an embedded question - what arthritis is - and is true if and only if Alice is in a knowledge relation to propositions that truly answer it.

Notice, however, that, for typical cases of ascriptions of the knowledge of what something is, we should not defend a view according to which they are true only if subjects know propositions that count as true, exhaustive answers to questions embedded in them. For this to be so when it comes to a typical case of ascription of the knowledge of what something is, such as (2), subjects would have to know, for every case of arthritis, that it is a case of arthritis. This would certainly require knowing the necessary and sufficient conditions for something to be a case of arthritis — or, as put by Burge (1993), it would require knowing the metaphysically correct definition of arthritis. Given that the concept of arthritis captures not a single disease, but a number of conditions that share similar symptoms, there are difficulties here which are specific for this concept and for others which are alike in this respect. In general, however, there is something close to a consensus in the literature that, as Laurence and Margolis (1999, p.14) say, "for most concepts, there simply aren't any definitions. Definitions have proven exceptionally difficult to come by...". As we have learnt from Wittgenstein (1953) and Fodor (1981), for instance, even ordinary concepts such as GAME and PAINT do not seem to be definable. So, I suggest that, 
when it comes to its truth conditions, ascriptions of the knowledge of what something is, such as (2), are closer to (4) than to (3), in that they are true if and only if one knows true answers to questions embedded in their what-clauses.

Let us suppose, for instance, that, unlike Burge's imagined individual, Alice has only true beliefs regarding arthritis, that lead her to characterise it in the following way:

(5) Arthritis is not a single disease, but a family of conditions that involve symptoms such as pain, swelling and stiffness in the joints.

Being in a knowledge relation to (5) seems clearly sufficient for Alice to know what arthritis is, supposing that she does not have false beliefs on the issue. But what to say of the individual imagined by Burge, who is in possession of beliefs that can also be expressed in terms of (5), but who also believes falsely that arthritis has affected his thigh? I discuss the issue in the next section.

\section{False beliefs, gradability and knowing in part what something is}

In the epistemological literature it is often remarked that ascriptions of the form " $S$ knows that $p$ " do not admit either comparison constructions such as "-er/more than", "less than", and "as much as" or proportional modifiers such as "in part", "for the most part" and "partly" (Stanley 2005; Pavese 2017). The following ascriptions, for example, seem clearly odd:

(6) ?Alice knows that Martin Scorsese directed Taxi Driver more than Peter does.

(7) ?Alice knows in part that Martin Scorsese directed Taxi Driver.

Ascriptions which admit the comparison constructions and proportional modifiers indicated above are said to be gradable. Given that ascriptions of the form " $S$ knows that $p$ " do not admit these constructions, it seems that they are, as put by Stanley (2005, p.37), "not gradable at all". ${ }^{9}$ Knowing that $p$ thus seems to be an all or nothing affair. Either one knows that $p$ or ones does not. Ascriptions of knowledgewh, involving expressions such as "knows who", however, typically do admit these constructions:

(8) Peter knows for the most part who came to the party in Patricia's house last night.

(9) Alice knows who came to the party in Patricia's house last night more than Peter does. 
So, it seems clear that ascriptions of knowledge-wh, such as ascriptions of knowing-who, are gradable. Thus, knowing-wh, unlike knowing that $p$, does not seem to be an all or nothing affair. Knowing-wh can come in degrees. ${ }^{10}$

It is no surprise then that the following ascriptions seem perfectly acceptable:

(10) Peter knows in part what arthritis is.

(11) Alice knows what arthritis is more than Peter does.

Let us suppose that Peter is in the situation imagined by Burge: he has a number of true beliefs regarding arthritis, but also believes that he has arthritis in his thigh - unlike Alice, who only has true beliefs on the issue. The reader will by now have anticipated what is to be the central suggestion of this paper. (10) is a true ascription that captures what Burge has in mind when he discusses the case of a subject who incompletely understands the concept of arthritis. And we can now add: (11) should also be true. More specifically, once we understand direct concept ascriptions in terms of ascriptions of the knowledge of what something is, and given the gradability of these ascriptions, the cases imagined by Burge (1979) in which subjects have false beliefs involving a concept - cases taken by Burge as being of incomplete understanding of concepts - can be treated as being cases in which one knows in part what something is. Thus, Peter can be said to know in part what arthritis is. Moreover, those who have only true beliefs involving a concept - such as that of arthritis - can be said to know what something is more than those who have false beliefs involving the same concept do. Thus, Alice can be said to know what arthritis is more than Peter does.

I take it that this a straightforward way of dealing with the cases imagined by Burge (1979), one that does not rely on the idea of "incomplete understanding of a concept", which critics have taken to be less than clear. Let me now develop this central point by way of dealing with three difficulties. First, it is important to notice that the natural readings of (10) and (11) seem to be different from those of (8) and (9). It will be instructive to start by discussing (8). As we have seen above, given Karttunen's (1977) account, (3) - Alice knows who came to the party in Patricia's house last night - is true if and only if Alice knows, of all the people that came to the party in Patricia's house last night, that they did come. Given this account, there should be no mystery when it comes to the truth-conditions of (8): (8) is true if and only if Peter knows, for most people who came to the party in Patricia's house last night, that they did come. ${ }^{11}$ Thus, knowing for the most part who came to the party in case in simply a matter - to put in terms similar to those of Groenendijk and Stokhof $(2011)^{12}$ - of one having an answer to the embedded question of the whoclause that mentions most - but not all — of the objects that satisfy the condition expressed by the interrogative. If Alice happens to know the complete list of those 
who came to the party in case, the list known by Peter is less than complete - he only knows that Mark and Anna came to the party, say.

Given this way of semantically treating (8), (9) can be dealt with in similar terms. Informally, (9) is true if and only if both Alice and Peter know a list of people who indeed came to the party, and Alice's list contain more names than Peter's list does.

The case imagined by Burge (1979) — and here illustrated in (10) - , however, brings us something new. It is not a matter of Peter's answer to the question of what arthritis is being less than exhaustive - after all, we have already argued that exhaustive answers are not to be expected for questions regarding what something is. Rather, he has a number of true beliefs regarding what arthritis is, but he also has a false belief on the issue. So, his answers to the question in case are not all true. Now, let us keep in mind the suggestion made earlier, according to which ascriptions of the knowledge of what something is are true if and only if one knows true answers to the questions embedded in what-clauses. Given this view, Peter can be said to know what arthritis is. That he knows it only in part is due precisely to the fact that one of his answers to the question in case is false. Given that Alice's answers to the question of what arthritis is are all true, it can then be said that she knows what arthritis is more than Peter does, as stated in (11).

Given the differences between the readings of (8) and (10), the following claim can be made: ascriptions of knowledge-wh admit proportional modifiers - such as "in part" - not only on occasions in which one knows answers to the embedded question of the wh-clause that mention some, but not all of the objects that satisfy the condition expressed by the interrogative; proportional modifiers may also be admitted on occasions in which most of the answers given to the question in case are true, but not all of them. ${ }^{13}$ That is precisely the case in (10).

A similar lesson applies to comparative constructions such as "more than". Ascriptions of knowledge-wh admit comparative constructions such as "more than" on occasions in which one subject knows answers to the question in case that mention more objects that satisfy the condition expressed by the interrogative than another subject's answer to the same question does. But these constructions may also be admitted on occasions in which one subject's answers to the question in case are all true, while some of the answers of another subject to these same questions are true, but not all of them, as is the case in (11).

Let me now deal with a second difficulty. I have suggested that, in order for ascriptions of the knowledge of what something is to be true, it need not be the case that subjects to whom knowledge is ascribed know true, exhaustive answers to questions embedded in what-clauses. It suffices that subjects know true answers to these questions. Should we say, then, that the knowledge of what something is typically partial knowledge, in the sense that subjects know true answers to the questions embedded in what-clauses that are less than complete? 
Strictly speaking, the answer to this question should be "yes". There seems to be nothing like a complete, exhaustive answer to the question of what arthritis is, and the same applies to most cases of knowing what something is. So, typically the knowledge of what something is happens to be partial. This does not mean, however, that we should, for most cases, introduce proportionality modifiers in ascriptions of this sort of knowledge. If we do so, we risk losing sight of important differences between subjects when it comes to their levels of expertise regarding the same issue. Consider, for instance, the following ascriptions:

(10) Peter knows in part what arthritis is.

(12) Joshua knows in part what arthritis is.

As we know, Peter has a false belief regarding arthritis. Now imagine that Joshua is an expert on the issue - a world-renowned rheumatologist, say. Strictly speaking, we could say that both (10) and (12) are true, albeit not exactly for the same reason. Joshua's knowledge is partial only because he does not know a complete, exhaustive answer to the question of what arthritis is. The same goes for Peter. But not only Peter does not know an exhaustive answer to the question in case - probably no one does -; he also has a false belief on the issue. This is an important difference between Peter and Joshua when it comes to their knowledge of what arthritis is, and one that should be reflected in our ascriptions of this piece of knowledge to them. When it comes to experts, we seek to convey with our ascriptions that these subjects are in a good epistemic position regarding the issue at hand. Ascriptions involving the proportional modifier "in part", however, convey precisely that the subject to whom knowledge is ascribed it not in a good enough epistemic position regarding the issue at hand - at least this seems to be so for most conversational contexts. By saying that Peter knows in part what arthritis is, for instance, we seek to pragmatically convey that he has a false belief on the issue. So, even if, strictly speaking, (12) is true, there are good pragmatic reasons for one to simply say that Joshua knows what arthritis is, and not that he knows it in part. When it comes to Peter, the opposite is true: there are good pragmatic reasons to say that the knows in part what arthritis is. ${ }^{14}$

I now turn to a third and final difficulty. Let us again consider (4), "Alice knows where to buy Italian newspapers in New York City". I have claimed that (4) is true if and only if Alice knows a true answer to the question embedded in it, where to buy Italian newspapers in New York City. Now imagine that Alice, besides knowing, of some place $P_{1}$ in NYC, that it is a place where she can buy Italian newspapers, she falsely believes of some other place $P_{2}$ that she can also buy Italian newspapers there $-P_{2}$, suppose, doesn't sell newspapers at all. Given the truth-conditions that we have presented for (4), the ascription would still be true. But would it? George (2013) has his doubts. According to him, "there is a great deal of reluctance to affirm it or 
proclaim it true", for half of the subject's beliefs "on the matter are just plain wrong" (2013, p.170). Mention-some questions - such as where to buy Italian newspapers in New York City - would then be sensitive to false answers (Theiler et al. 2016), in that false beliefs expressed in false answers to these questions would affect the truth of ascriptions of knowledge-wh to subjects in possession of these beliefs.

It could then be objected that the same goes for (11). Given that Peter has a false belief regarding what arthritis is, (11) would be simply false. Peter wouldn't know what arthritis is at all.

Now, notice that, as George himself (2013) remarks, it certainly matters when it comes to our intuitions on the issue of whether an ascription such as (11) is true or not that we are working under the assumption that half of the subject's beliefs on the issue at hand are false. If Alice happened to know, say, of ten places in NYC that they sell Italian newspapers, and happened to be wrong regarding only one other place, I take it that we would be temped to say that (11) may not be true as it stands, but that (13) may indeed be taken as true:

Alice knows in part where to buy Italian newspapers in New York City.

Similarly, if Peter had only two beliefs regarding arthritis, one true and the other false, we would, I think, be tempted to say that he does not know what arthritis is at all. But it is not for nothing that Burge (1979) builds his example as one in which a subject has a number of true beliefs on the matter, and one false belief. The proportion of true beliefs in respect to false ones certainly has an important role to play in Burge's intuition that the imagined subject has an incomplete understanding of the concept of arthritis. ${ }^{15}$ I think we should follow Burge here in denying that a subject — such as Peter - simply doesn't know what arthritis is. However, if the claims made in this paper are on the right track, Burge's case is made clearer when we take a subject such as Peter not as having an incomplete understanding of the concept of arthritis, but as knowing in part what arthritis is.

\section{Conclusion}

In this paper, I have argued that the cases imagined by Burge (1979) as involving incomplete understanding of concepts can be made clearer given an account of direct concept ascriptions according to which these ascriptions are to be analysed in terms of ascriptions of the knowledge of what something is, for, with this account in place, and given the gradability of ascriptions of the knowledge of what something is, we can understand these cases as being ones in which subjects know in part what something is. This way of dealing with these cases makes justice to Burge's intuitions on the issue and it has the advantage of avoiding the idea of subjects incompletely understanding concepts, which critics have taken to be less than clear. 


\section{References}

Bach, K. 1987. Thought and Reference. Oxford: Oxford University Press.

Ball, D. 2009. There Are No Phenomenal Concepts. Mind 118(472): 935-962.

Burge, T. 1979. Individualism and the Mental. Midwest Studies in Philosophy 4(1): 73-121.

Burge, T. 1993. Concepts, Definitions, and Meaning. Metaphilosophy 24(4): 309-27.

Dretske, F. 1981. The Pragmatic Dimension of Knowledge. Philosophical Studies 40(3): 36379.

Fodor, J. 1981. The Present Status of the Innateness Controversy. In: RePresentations: Philosophical Essays on the Foundations of Cognitive Science, p. 257-316. Cambridge, MA: MIT Press.

George, B. R. 2013. Knowing-Wh, Mention-Some Readings, and Non-Reducibility. Thought 2(2): 166-77.

Greonendijk, J. \& Stokhof, M. 1982. Semantic Analysis of 'Wh'-complements. Linguistics and Philosophy 5(2): 175-233.

Greonendijk, J. \& Stokhof, M. 1984. Studies on the Semantics of Questions and the Pragmatics of Answers. Joint PhD. diss., University of Amsterdam.

Greonendijk, J. \& Stokhof, M. 2011. Questions. In: J.V. Benthem \& A.T.Meulen (ed.), Handbook of Logic and Language, p.1059-1032. London: Elsevier.

Karttunen, L. 1977. Syntax and Semantics of Questions. Linguistics and Philosophy 1(1): 344.

Laurence, S. \& Margolis, E. 1999. Concepts and Cognitive Science. In: E.Margolis \& S. Laurence (ed.), Concepts: Core Readings, p. 3-81. Cambridge, MA: MIT Press.

Pavese, C. 2017. Know-How and Gradability. Philosophical Review 126(3): 345-383.

Peacocke, C. 1992. A Study of Concepts. Cambridge, MA: MIT Press.

Stanley, J. 2005. Knowledge and Practical Interests. Oxford: Oxford University Press.

Stanley, J. 2011. Know How. Oxford: Oxford University Press.

Stanley, J. \& Williamson, T. 2001. Knowing How. The Journal of Philosophy 98(8): 411-44.

Theiler, N.; Roelofsen, F. \& Aloni, M. 2016. Truthful Resolutions: A New Perspective on FalseAnswer Sensitivity. Semantics and Linguistic Theory 26: 122-41.

Travis, C. 2000. Unshadowed Thought: Representation in Thought and Language. Cambridge, MA: Harvard University Press.

Wikforss, Å. 2001. Social Externalism and Conceptual Errors. Philosophical Quarterly 51 (203): 217-231.

Wikforss, А. 2017. Incomplete Understanding of Concepts. In: Oxford Handbooks Online. https://www.oxfordhandbooks.com/view/10.1093/oxfordhb/9780199935314.001.0001/ oxfordhb-9780199935314-e-49. Access: 17/03/2020.

Wittgenstein, L. 1953. Philosophical Investigations. Trans. G.E.M. Anscombe. Oxford: Blackwell.

\section{Notes}

${ }^{1}$ Burge (1979, p.78) further argues that, in a counterfactual situation in which the term "arthritis" applies to various rheumatoid ailments, including those that affect the thigh, the 
term would express a concept different from our concept of arthritis, and if a subject were to utter "I have arthritis in my thigh" in this situation, she would be expressing a true belief involving this very concept. Which concept a word expresses would then depend not only on internal aspects of the subject, but also on the subject's social environment. This important step of Burge's thought-experiment will not be relevant for our purposes.

${ }^{2} \mathrm{~A}$ number of recent debates have been influenced by Burge's view, such as the one regarding the existence of phenomenal concepts, that is, concepts that refer to the phenomenal properties of our experiences (see Ball 2009).

${ }^{3}$ Direct concept ascriptions such as (1) should be distinguished from what we can call "indirect concept ascriptions", that is, ascriptions of propositional attitudes to subjects in which concepts figure.

${ }^{4}$ Notice that I am not claiming that all ascriptions of concepts should be understood in terms of ascriptions of the knowledge of what something is. I am not here concerned, for instance, with ascriptions of concepts made to non-human animals. I am only concerned for the present purposes with ascriptions of concepts made within conversational settings. Thus I am not engaged in the project of seeking to identify necessary and sufficient conditions for one to have a concept. This also means that the notion of analysis in play here is less embracing and ambitious than the one in play in traditional projects of philosophical analysis.

${ }^{5}$ According to Stanley and Williamson (2001) and Stanley (2011), ascriptions of know how can also be treated in terms of the standard semantical framework for ascriptions of knowledge-wh.

${ }^{6}$ In more general terms, an answer can be said to be exhaustive if it mentions all the objects that satisfy the condition expressed by the interrogative (Groenendijk and Stokhof 2011, p.1117). Notice that there is controversy here in that Groenendijk and Stokhof (1982) argue, against Karttunen (1977), that in order for an ascription such as (3) to be true, Alice should know not only of all the people that came to the party in Patricia's house that they did. She should also know, for all the people that did not come, that they did not come. This latter form of exhaustivity is called strong exhaustivity, in opposition to the weak exhaustivity (cf. Groenendijk and Stokhof 1984) claimed by Karttunen (1977) for these cases. As put by Groenendijk and Stokhof (2011, p.1116), "a weakly exhaustive answer provides a complete list, a strongly exhaustive answer contains in addition the closure condition stating 'and that's all, folks"'.

${ }^{7}$ The question of where to buy Italian newspapers in NYC is typically taken as a mentionsome, non-exhaustive question, in that answers to it are acceptable if they "mention some object that satisfies the condition expressed by the interrogative" (Groenendijk and Stokhof 2011, p.1117), thus not conforming to the kinds of exhaustivity considered in note 6 .

${ }^{8}$ George (2013) suggests that an ascription such as (4) also demands for its truth that Alice does not have any false beliefs regarding where to buy Italian newspapers in NYC. I will discuss this issue in section 3 .

${ }^{9} \mathrm{He}$ is here in agreement with Dretske (1981, p.363), who writes that "knowing that something is so, unlike being wealthy or reasonable, is not a matter of degree".

${ }^{10}$ Examples of ascriptions involving expressions such "knows where", "knows when" etc. could also be given, such as "Alice partly knows where the Yankee Stadium is", "Joe knows when the War of the Roses finished more than Alice does".

${ }^{11}$ Pavese (2017) calls this the counting approach to gradability. 
${ }^{12}$ See note 7.

${ }^{13}$ We may be tempted here to ask how many answers are allowed to be false so that one can still know in part what something is. I doubt that there is a general answer to this question, one that does not take specific conversational contexts in which ascriptions are made into account.

${ }^{14}$ Notice that framing the issue in these terms also allows us to make justice to Burge's (1979) view that we semantically defer to experts when using terms such as "arthritis". We do so because we believe that experts are in a better epistemic position than us when it comes to these matters.

${ }^{15}$ Again, we may be tempted to ask here how many true beliefs we need to have and how many false beliefs we are allowed to have if we are to know in part what something is. As suggested in note 13, I think we should avoid the temptation of providing a general answer here.

\section{Acknowledgments}

I would like to thank an anonymous referee for his/her comments and CNPq for funding this research. 